\title{
Rehabilitation with implant-retained removable dentures and its effects on perioral aesthetics: a prospective cohort study
}

This article was published in the following Dove Press journal:

Clinical, Cosmetic and Investigational Dentistry

30 September 2016

Number of times this article has been viewed

\author{
Saturnino Marco Lupi \\ Matteo Cislaghi \\ Silvana Rizzo \\ Ruggero Rodriguez y Baena
}

Department of Clinical Surgical, Diagnostic and Pediatric Sciences, University of Pavia, Pavia, Italy
Correspondence: Ruggero Rodriguez y Baena

Department of Clinical Surgical, Diagnostic, and Pediatric Sciences, University of Pavia, Piazzale Golgi 2, 27100, Pavia, Italy

Tel +3903825I 6255

Email ruggero.rodriguez@unipv.it
Background: The onset of perioral wrinkles often prompts patients to request treatment. This aesthetic deterioration linked to aging may be associated with tooth and alveolar bone loss in fully edentulous patients.

Purpose: To evaluate perioral wrinkles before and after maxillary and mandibular rehabilitation with implant-retained dentures in fully edentulous patients.

Methods: In this prospective cohort, single-center, blinded study, patients requiring maxillary and mandibular rehabilitation with implant-retained dentures were enrolled. The patients were photographed in the same position before and after oral rehabilitation. Wrinkles were evaluated in the photographs by blinded observers using validated rating scales. The following parameters were analyzed: upper and lower radial lip lines, marionette lines, upper and lower lip fullness, nasolabial folds, corner of the mouth lines, and the labiomental crease. Statistical analysis was performed using the Wilcoxon signed ranks test for paired data, with $P<0.05$ considered significant.

Results: Upper and lower implant-retained dentures were applied in 31 patients (15 males; mean \pm standard deviation age $62.13 \pm 8.69$ years, range $47-77$ years). The oral rehabilitation procedures significantly improved $(P<0.05)$ the upper and lower radial lip lines, marionette lines, upper and lower lip fullness, the nasolabial folds, and the corner of the mouth lines.

Conclusion: Maxillary and mandibular rehabilitation with implant-retained dentures in fully edentulous patients improves perioral aesthetics. Patients requiring oral rehabilitation and desiring perioral aesthetic improvement could benefit from treatment with this type of prosthesis.

Keywords: aesthetic medicine, perioral wrinkles, implant-retained denture, overdenture

\section{Introduction}

Increased life expectancy is one of the greatest global public health challenges in developed countries. In Italy, the proportion of the population aged $\geq 65$ exceeds $21 \%$. In Western Europe, the proportion exceeds $16 \%$, and in the US, Australia, and Oceania, it is $13 \% .^{1-4}$

In parallel with changes in the age pyramid, age-related challenges arise, and interest in combating visible signs of skin aging increases. Aging of the face through a dynamic process characterized by the degeneration of both the soft tissues and the bone structure leads to an altered relationship between these components. ${ }^{5}$ Skin aging is a gradual, natural process classified as intrinsic or extrinsic, and involves genetic, hormonal, and environmental mechanisms. Intrinsic aging, also called chronologic aging, may be influenced by exogenous factors such as smoking, alcohol consumption, and exposure to ultraviolet radiation, which are considered the main factors of extrinsic aging. ${ }^{6}$ 
Wrinkle formation is a consequence of these processes. ${ }^{7-12}$ Requests for cosmetic procedures with permanent or temporary filler to reduce the number and depth of wrinkles and to provide an appropriate volume to the lips ${ }^{13,14}$ are increasing with variable results. ${ }^{15}$ Reports of more or less serious complications are also increasing in number, however, even in the case of safe molecules such as hyaluronic acid. ${ }^{16-18}$

Degenerative processes involving the teeth (tooth loss, poorly executed prosthetic rehabilitation, neglect of oral hygiene, etc) also contribute to aging the appearance of a face. ${ }^{19}$ In fact, a face devoid of a smile with complete dentures appears more aged than one with a complete set of teeth, both subjectively and objectively with regard to the facial structures. ${ }^{20}$ In addition, the condition of edentulism is associated with a well-known progressive centripetal resorption of the alveolar process of the maxillary bones, ${ }^{21}$ with reduced support and stretching of the perioral tissues exerted by the teeth and underlying bone, and consequent worsening of wrinkles and lip volume.

\section{Objective}

To evaluate the effect of rehabilitation through removable implant-retained dentures on perioral wrinkles.

\section{Materials and methods}

This prospective cohort, single-center trial, conducted in accordance with Good Clinical Practices in Human Beings, involved 31 subjects who underwent rehabilitation of the upper and lower jaws with implant-retained dentures. ${ }^{22}$ This study was approved by the Ethic Committee of Pavia State, Fondazione IRCCS Policlinico "San Matteo", Pavia, Italy (document 09/21/2016, n. 20020001513). The subjects were enrolled consecutively from among those who accessed the Oral Surgery and Implantology Service of the Department of Clinical Surgical, Pediatric, and Diagnostic Sciences at the University of Pavia.

The surgical ${ }^{23}$ and prosthetic procedures used for all patients were those typically used by our team and included, briefly: medical history and clinical examination, obtaining consent, radiographic and hematologic evaluation, antibiotic prophylaxis, implant surgery, submerged healing for 6-8 weeks, second surgery, dental impressions, prosthetic proof-of-concept, and final restoration. The skin at the perioral tissue level was intact in all subjects, and none of the patients were taking topical or systemic medications or substances that could interfere with the evaluation of perioral wrinkles. Patients were informed about the purpose of the research and the use of any obtained photographs in which patients would not be recognizable. All patients freely provided their written consent to be included in this study and to the use of facial images for the purposes of the study. Perioral wrinkles and lip volume were evaluated by comparing photos at the beginning and end of the study for each case examined.

The scale proposed by Lamperle et $\mathrm{al}^{24}$ was used for evaluation of perioral wrinkles, in which a score from 0 to 5 is assigned according to the increasing severity of the wrinkles. Lip volume was graded according to the lip fullness scale, ${ }^{25}$ in which a score from 0 (very thin) to 4 (full) is assigned. The patients were photographed before and after the rehabilitation program to compare the aesthetics of the perioral soft tissues with and without the final prosthesis in place. In this study, the following parameters were analyzed: upper and lower radial lip lines, marionette lines, upper and lower lip fullness, nasolabial folds, corner of the mouth lines, and labiomental crease.

Personal data and medical history were also collected, with an emphasis on intrinsic and extrinsic factors that promote skin aging: ${ }^{26}$ prolonged periods of sun exposure, smoking, diet, and hormone replacement therapy.

The photographs were obtained using a professional digital SLR camera Fujifilm ${ }^{\circledR}$ S5 Pro (FUJIFILM Corporation, Tokyo, Japan), with a Nikkor ${ }^{\circledR} 35 \mathrm{~mm}$ (Nikon Corporation, Tokyo, Japan) fixed focal length lens. The images were recorded in high definition and saved in RAW format to allow for the optimum setting of image parameters in post-processing.

Two full-face photographs for each patient were obtained: one with and one without the dentures. The images were obtained of the frontal face position, with the mouth of the patient in rest position. To avoid bias due to the shooting point position, the camera was mounted on a tripod and positioned $1 \mathrm{~m}$ from the patient's face, at the height of the mouth. Photographs of the smile were not obtained to avoid the possibility of biasing the observers. Once taken, the pictures were cut to place only the perioral area in the foreground (Figure 1). The images were identified by a label code and randomly inserted into a PowerPoint ${ }^{\circledR}$ (Microsoft Corporation, Redmond, WA, USA) presentation with a black background. After proper training, two observers independently and blindly evaluated the clinical images using an $\mathrm{Mac}^{\circledR}$ computer (Apple, Cupertino, CA, USA) with a 27 " monitor in a dark room. Disagreements in the scoring between the observers were resolved through discussion. Data were collected using a diagram drawn by the authors (Figure 2) and then input into an Excel $^{\circledR}$ (Microsoft Corporation, Redmond, WA, USA) spreadsheet.

\section{Statistical analysis}

The collected data were statistically analyzed using R Core Team (2013); R: A language and environment for statistical 
A

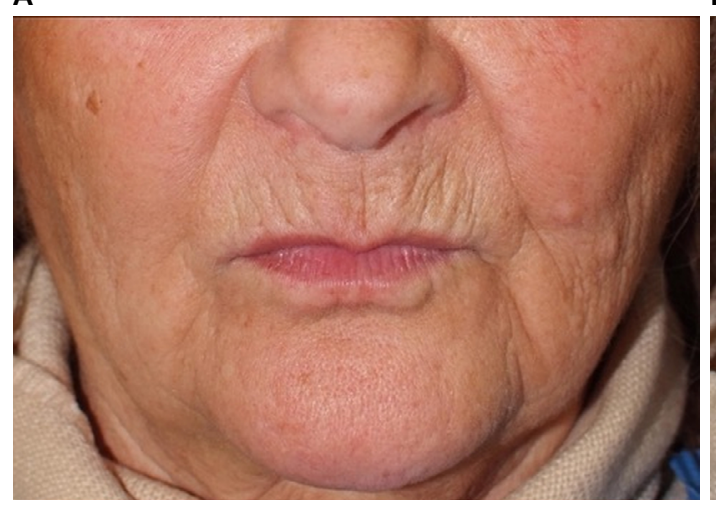

Figure I Female patient (59 years of age) before (A) and after (B) rehabilitation of the maxilla and mandible with the overdenture.
B

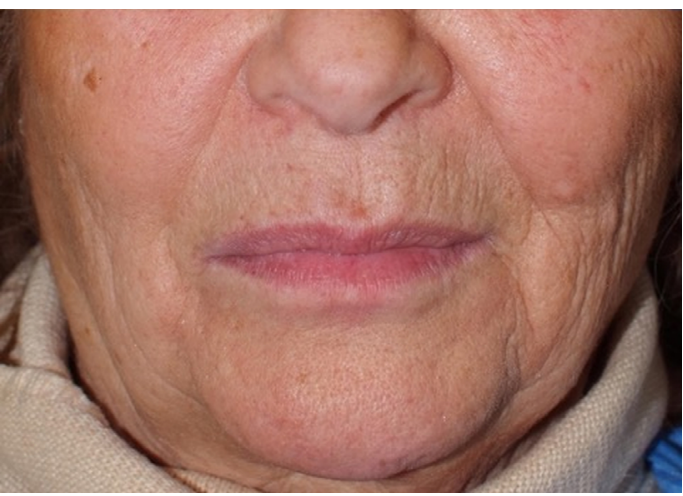

computing (R Foundation for Statistical Computing, Vienna, Austria; http://www.R-project.org/).

Because the results were scored subjectively, the observations were treated as ordinal qualitative variables using the Wilcoxon test of ranks for paired data to determine the statistical significance.

\section{Results}

In the period between January 2012 and June 2016, 31 patients ( 15 males), between 47 and 77 years of age (mean \pm standard deviation, 62.13 \pm 8.69 years), were enrolled at the Service of Oral Surgery and Implant Dentistry of the Department of Clinical Surgical, Pediatric, and Diagnostic Sciences at the University of Pavia. All patients completed the study, and 31 mandibular and maxillary implant-prosthetic rehabilitations were completed. All implant-retained rehabilitations were successfully completed.

Rehabilitation with overdentures produced statistically significant improvement in the upper and lower radial lip lines, marionette lines, upper and lower lip fullness, nasolabial folds, and corner of the mouth lines (Table 1; Figures 3-9).

\section{Discussion}

This study evaluated the effect of implant-retained denture rehabilitation ${ }^{22}$ on perioral wrinkles in edentulous patients. The rating scale used is simple to read and facilitates comparison of the photographs of the observed cases. Moreover, the high definition photographs obtained with a professional camera allowed for better visualization of wrinkles because the images could be magnified to highlight the details of the observed elements.

Statistical analysis revealed that implant-retained denture rehabilitation significantly improved the aesthetics of the perioral soft tissues with regard to almost all wrinkle types evaluated. Statistically significant improvements were observed for the upper and lower radial lip lines, marionette lines, upper and lower lip fullness, nasolabial folds, and the corner of the mouth lines. Only the labiomental crease showed no significant improvement.

Numerous studies have evaluated oral and perioral aesthetics, focusing on the form, ${ }^{27,28}$ structure, ${ }^{29}$ color, ${ }^{30}$ and position ${ }^{31,32}$ of the teeth, and the influence of prosthetic rehabilitation on the aesthetics of the smile. ${ }^{33}$ This is the first study to evaluate the influence of implant-retained rehabilitation on the appearance of perioral wrinkles and lip volume.

With aging, the whole organism undergoes structural changes and at the same time the skin undergoes significant alterations due to intrinsic or extrinsic factors. These processes result in the loss of elasticity and firmness of the tissue, leading to the formation of wrinkles. In addition to this damage, loss of the teeth and consequent resorption of alveolar bone tissues considerably worsens the overall appearance of the face, with an accentuation of the typical features of aging: wrinkles, skin laxity, loss of tone, a decreased intermaxillary vertical dimension, mandibular prognathism, and lowering of the nasal tip. ${ }^{19,20}$

Table I Statistical findings of the effects of overdenture treatment on wrinkles and fullness of the lips

\begin{tabular}{ll}
\hline Perioral sign & $\boldsymbol{P}$-value \\
\hline Upper radial lip lines & $<0.00 \mathrm{I}$ \\
Lower radial lip lines & $<0.00 \mathrm{I}$ \\
Marionette lines & $<0.00 \mathrm{I}$ \\
Upper lip fullness & $<0.00 \mathrm{I}$ \\
Lower lip fullness & $<0.00 \mathrm{I}$ \\
Nasolabial folds & $<0.01$ \\
Corner of the mouth lines & $<0.00 \mathrm{I}$ \\
Labiomental crease & Not significant \\
\hline
\end{tabular}




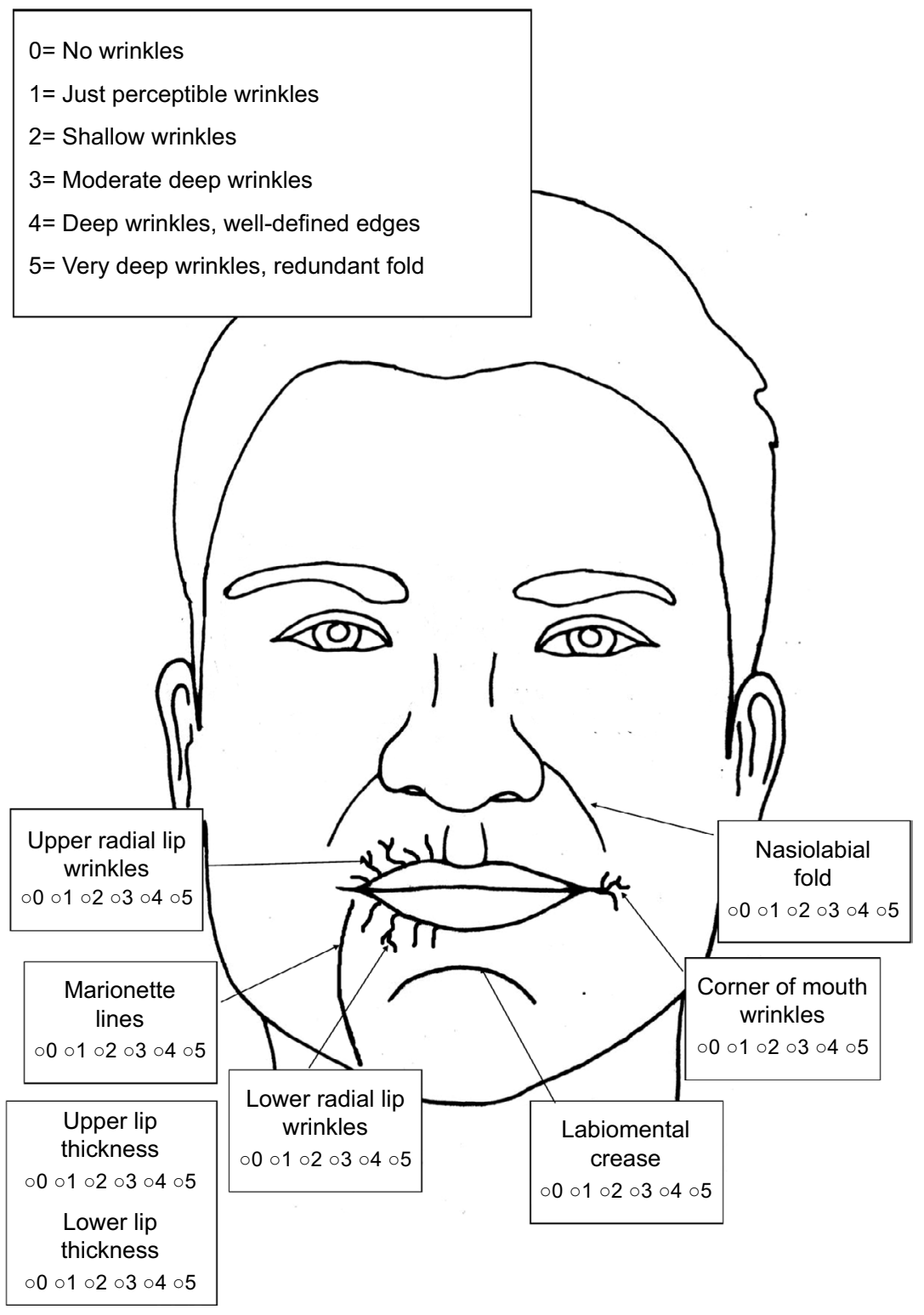

Figure 2 Diagram used for evaluation of the photographs.

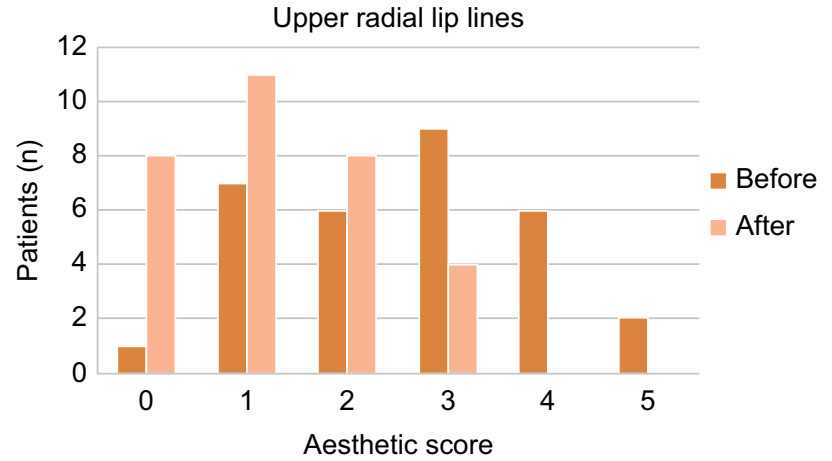

Figure 3 Graph of the distribution of the upper radial lip lines, showing a decrease in the severity of wrinkles after treatment.

Implant-retained denture rehabilitation allows - in addition to the restoration of masticatory function and the intraoral aesthetic - for restoration of the volume of the alveolar process and thus leads to optimal support of the perioral

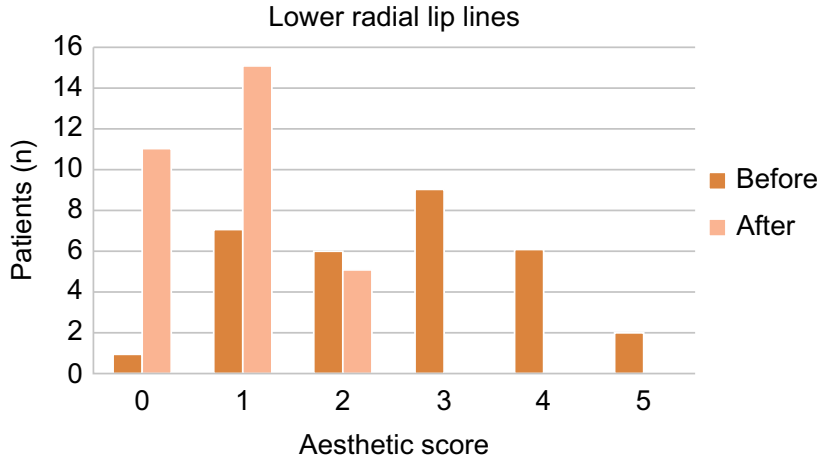

Figure $4 \mathrm{Graph}$ of the distribution of the lower radial lip lines, showing a decrease in the severity of wrinkles after treatment.

soft tissues. Therefore, proper prosthetic rehabilitation may help to improve the aesthetics of the perioral skin, reducing the amount and size of wrinkles involved in face aging and providing greater support to the lips. Moreover, besides 


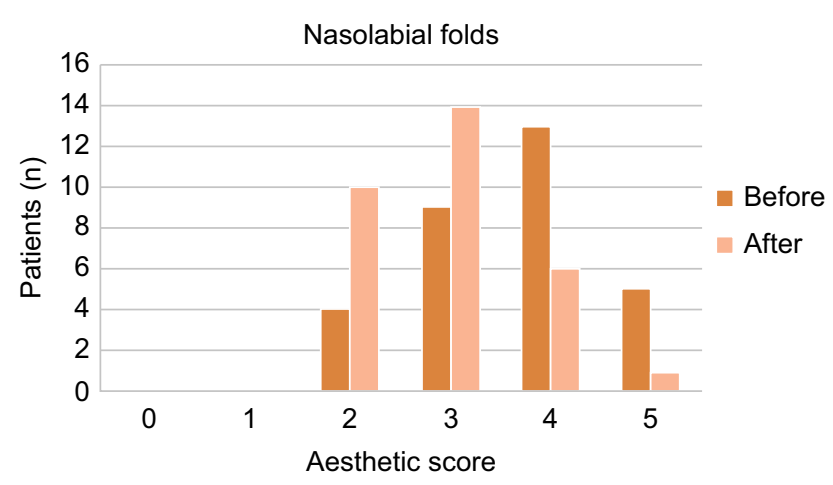

Figure 5 Graph of the distribution of the nasolabial folds, showing a decrease in the severity of wrinkles after treatment.

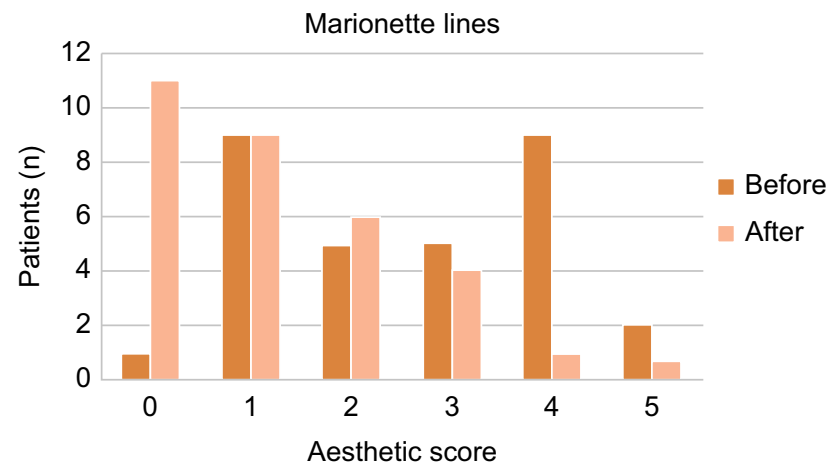

Figure 6 Graph of the distribution of the marionette lines, showing a decrease in the severity of wrinkles after treatment.

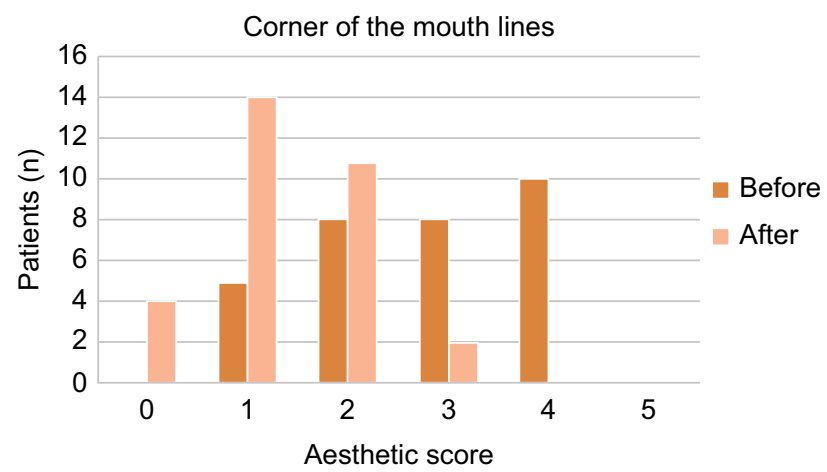

Figure 7 Graph of the distribution of the corner of the mouth lines, showing a decrease in the severity of wrinkles after treatment.

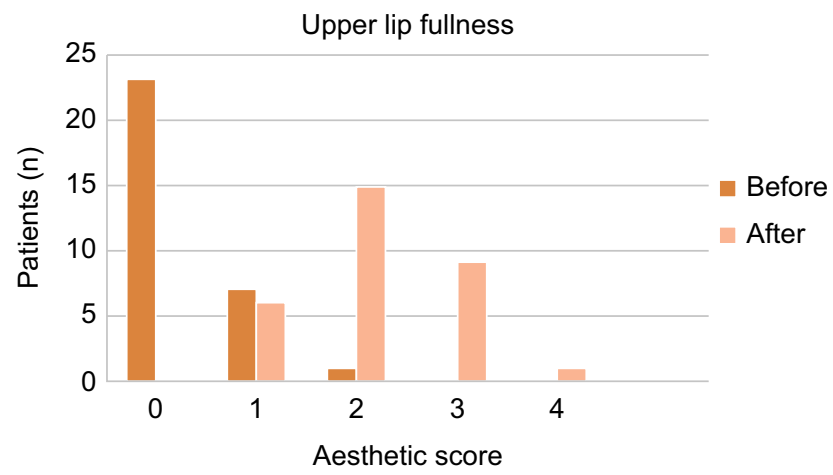

Figure $8 \mathrm{Graph}$ of the distribution of the upper lip fullness, showing improvement of the lip profile after treatment.

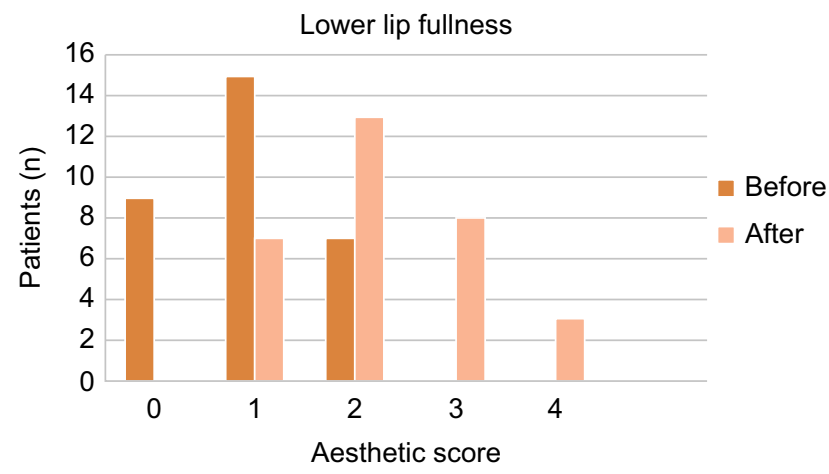

Figure 9 Graph of the distribution of the lower lip fullness, showing improvement of the lip profile after treatment.

the advantages of being less expensive than a full-arch implant-supported fixed prosthesis and providing greater stability compared to the traditional removable denture, overdentures are indicated even in cases in which the patient desires aesthetic improvement of the perioral soft-tissues. In addition, rehabilitation with overdentures allows for easier maintenance of hygiene around implants compared to a fullarch implant-supported fixed prosthesis. ${ }^{34}$ While traditional removable dentures may also somewhat restore lost volume and provide optimum support to the soft tissues, these benefits are limited by the need to optimize stability. In the case of overdentures, which have extremely superior stability, modeling of the prosthetic flanges and positioning of the teeth can be oriented not only to the recovery of optimal masticatory function, but also to the appropriate restoration of lost volume and support of soft tissues. The results of this study highlight the importance of a comprehensive assessment that includes the dental situation of patients in need of an aesthetic medical intervention to improve the appearance of perioral tissues.

Further research should be conducted to assess whether there are significant differences between the perioral aesthetics of full-arch implant-supported fixed prostheses and implant-retained denture rehabilitation.

\section{Conclusion}

A global treatment plan that aims to restore facial aesthetics in fully edentulous patients should consider implant-retained denture rehabilitation to provide adequate deep support of the perioral soft-tissue. In these patients, the use of aesthetic medicine techniques such as fillers may benefit from dental rehabilitation. In fully edentulous patients, overdentures can improve the aesthetics of perioral wrinkles.

\section{Disclosure}

The authors report no conflicts of interest in this work. 


\section{References}

1. Moran A. North America. Glob Heart. 2014;9(1):29-34.

2. Moran A. Australasia. Glob Heart. 2014;9(1):47-52.

3. Mazzola P, Rimoldi SM, Rossi P, et al. Aging in Italy: The Need for New Welfare Strategies in an Old Country. Gerontologist. 2015;56(3):383-390.

4. Moran A. Western Europe. Glob Heart. 2014;9(1):83-88.

5. Kahn DM, Shaw RB. Overview of current thoughts on facial volume and aging. Facial Plast Surg. 2010;26(5):350-355.

6. Landau M. Exogenous factors in skin aging. Curr Probl Dermatol. 2007;35:1-13.

7. Bauman L. CosmoDerm/CosmoPlast (human bioengineered collagen) for the aging face. Facial Plast Surg. 2004;20(2):125-128.

8. Contet-Audonneau JL, Jeanmaire C, Pauly G. A histological study of human wrinkle structures: comparison between sun-exposed areas of the face, with or without wrinkles, and sun-protected areas. Br J Dermatol. 1999;140(6): 1038-1047.

9. Gilchrest BA. A review of skin ageing and its medical therapy. $\mathrm{Br} J$ Dermatol. 1996;135(6):867-875.

10. Jenkins G. Molecular mechanisms of skin ageing. Mech Ageing Dev. 2002;123(7):801-810.

11. Luebberding S, Krueger N, Kerscher M. Mechanical properties of human skin in vivo: a comparative evaluation in 300 men and women. Skin Res Technol. 2014;20(2):127-135.

12. Roh DS, Du Y, Gabriele ML, Robinson AR, Niedernhofer LJ, Funderburgh JL. Age-related dystrophic changes in corneal endothelium from DNA repair-deficient mice. Aging Cell. 2013;12(6):1122-1131.

13. Lorenc ZP. Techniques for the optimization of facial and nonfacial volumization with injectable poly-l-lactic acid. Aesthetic Plast Surg. 2012;36(5):1222-1229.

14. Wollina U. Perioral rejuvenation: restoration of attractiveness in aging females by minimally invasive procedures. Clin Interv Aging. 2013;8:1149-1155.

15. Wang Y, Kotsis SV, Chung KC. Applying the concepts of innovation strategies to plastic surgery. Plast Reconstr Surg. 2013;132(2): 483-490.

16. Hachach-Haram N, Kirkpatrick WN. Midface-lifting: evolution, indications, and technique. Facial Plast Surg. 2013;29(4):289-294.

17. Bloom JD, Immerman SB, Rosenberg DB. Face-lift complications. Facial Plast Surg. 2012;28(3):260-272.

18. Wilson YL, Ellis DA. Permanent soft tissue fillers. Facial Plast Surg. 2011;27(6):540-546.

19. Ozturk CN, Ozturk C, Bozkurt M, Uygur HS, Papay FA, Zins JE. Dentition, bone loss, and the aging of the mandible. Aesthet Surg J. 2013;33(7):967-974.
20. Leveque JL, Goubanova E. Influence of age on the lips and perioral skin. Dermatology. 2004;208(4):307-313.

21. Cawood JI, Howell RA. A classification of the edentulous jaws. Int $J$ Oral Maxillofac Surg. 1988;17(4):232-236.

22. Carlsson GE. Implant and root supported overdentures - a literature review and some data on bone loss in edentulous jaws. $J$ Adv Prosthodont. 2014;6(4):245-252.

23. Rizzo S, Zampetti P, Rodriguez Y Baena R, Svanosio D, Lupi SM. Retrospective analysis of 521 endosseous implants placed under antibiotic prophylaxis and review of literature. Minerva Stomatol. 2010;59(3):75-88.

24. Lemperle G, Holmes RE, Cohen SR, Lemperle SM. A classification of facial wrinkles. Plast Reconstr Surg. 2001;108(6):1735-1750; discussion 1751-1732.

25. Carruthers A, Carruthers J, Hardas B, et al. A validated lip fullness grading scale. Dermatol Surg. 2008;34(Suppl 2):S161-S166.

26. Paes EC, Teepen HJ, Koop WA, Kon M. Perioral wrinkles: histologic differences between men and women. Aesthet Surg J. 2009;29(6):467-472.

27. Chang CA, Fields HW Jr, Beck FM, et al. Smile esthetics from patients' perspectives for faces of varying attractiveness. Am J Orthod Dentofacial Orthop. 2011;140(4):e171-e180.

28. Witt M, Flores-Mir C. Laypeople's preferences regarding frontal dentofacial esthetics: tooth-related factors. $J$ Am Dent Assoc. 2011;142(6):635-645.

29. Fletcher P. Biologic rationale of esthetic crown lengthening using innovative proportion gauges. Int $J$ Periodontics Restorative Dent. 2011;31(5):523-532.

30. Brezniak N, Turgeman R, Redlich M. Incisor inclination determined by the light reflection zone on the tooth's surface. Quintessence Int. 2010;41(1):27-34.

31. Lombardo L, Berveglieri C, Guarneri MP, Siciliani G. Anterior dental alignment and smile: perception and sensations in a sample of 8- to 10-year-old children and their parents. Orthodontics (Chic.). 2011;12(4):366-377.

32. Foulger TE, Tredwin CJ, Gill DS, Moles DR. The influence of varying maxillary incisal edge embrasure space and interproximal contact area dimensions on perceived smile aesthetics. Br Dent J. 2010;209(3):E4.

33. Tortamano P, Camargo LO, Bello-Silva MS, Kanashiro LH. Immediate implant placement and restoration in the esthetic zone: a prospective study with 18 months of follow-up. Int J Oral Maxillofac Implants. 2010;25(2):345-350.

34. Lupi SM, Granati M, Butera A, Collesano V, RodriguezY Baena R. Airabrasive debridement with glycine powder versus manual debridement and chlorhexidine administration for the maintenance of peri-implant health status: a six-month randomized clinical trial. Int J Dent Hyg. Epub 2016 Feb 4.
Clinical, Cosmetic and Investigational Dentistry

\section{Publish your work in this journal}

Clinical, Cosmetic and Investigational Dentistry is an international, peer-reviewed, open access, online journal focusing on the latest clinical and experimental research in dentistry with specific emphasis on cosmetic interventions. Innovative developments in dental materials, techniques and devices that improve outcomes and patient satisfac-
Dovepress

tion and preference will be highlighted. The manuscript management system is completely online and includes a very quick and fair peerreview system, which is all easy to use. Visit http://www.dovepress. $\mathrm{com} /$ testimonials.php to read real quotes from published authors. 